\title{
O MESSIANISMO SEBASTIÂNICO NO REINO DA PEDRA BONITA (1836-1838): DISCUSSÕES E INTERPRETAÇÕES A PARTIR DE UMA BIBLIOGRAFIA PSICANALÍTICA
}

DAVI RODRIGUES BOTE ${ }^{1}$

Resumo: Este artigo analisa relações entre o sanguinário episódio do Reino da Pedra Bonita (1836-1838) — movimento sebastianista no sertão pernambucano, em São José do Belmonte (PE) - com leituras de matriz psicanalítica, a fim de caracterizar alguns pormenores deste movimento mítico profético segundo conceitos como intersubjetividade, massa e líder. $\mathrm{O}$ foco se encontra nas complexas relaçóes intragrupais e o papel desempenhado pelos 1) fatores culturais e tradicionais que legaram a possibilidade da construção simbólica do movimento, 2) indivíduos comuns - embebidos da ideia do retorno do messias Sebastião, símbolo libertador e provedor - e 3) os líderes, ou reis, ou mediadores deste encontro, figuras controversas responsáveis pela organização e funcionamento do reino. Mostraremos como o episódio da Pedra Bonita evoluiu de um agrupamento com um fim delimitado a uma organização amorfa e violenta com traços da horda primitiva descrita por Sigmund Freud.

Palavras-chave: História. Messianismo. Psicanálise. Relações Humanas.

1 INTRODUÇÃO

O incidente do Reino da Pedra Bonita não foi o primeiro de caráter messiânico no Brasil. Outros como este, mais expressivamente, ocorreram de forma semelhante no Nordeste e no Sul, os quais serviram de inspiração literária a nomes como Euclides da Cunha, José Lins do Rego e Ariano Suassuna. Todas essas manifestações grupais ganharam especificidades à luz da época em que ocorreram, portanto devem ser estudadas e compreendidas singularmente a partir dos elementos históricos que compuseram as narrativas; do contrário, simplificar-se-iam as leituras sobre os fenômenos messiânicos, generalizando elementos e imaginários tão únicos quanto poderiam.

1 Davi Rodrigues Bote é graduado em Geografia pela Universidade de São Paulo. davi.bote@usp.br 
O messianismo sebastiânico no Reino da Pedra Bonita (1836-1838): discussões e interpretações a partir de uma bibliografia psicanalítica

O presente artigo tem como objetivo analisar, sob o escopo da psicologia das relações humanas, fenômenos intersubjetivos que compóem o evento conhecido como incidente do Reino da Pedra Bonita. Para realizar tal tarefa, partimos de alguns pressupostos enunciados por Nelson Ernesto Coelho Junior, quem apresenta diferentes formas de se abordar as relações intersubjetivas. Sendo assim, o texto apresentará uma organização a partir dos conceitos de dimensóes transubjetiva e intrapsíquica, ficando, portanto, dividido em três partes além da introdução. A primeira consiste numa leitura da dimensão da transubjetividade, buscando compreender quais fenômenos da alteridade compóem a subjetividade dos participantes; a segunda parte trata da dimensão intrapsíquica, na qual serão analisadas, separadamente, as personagens atuantes que, através dos modos de se comportarem e se relacionarem com o outro, possamos identificar elementos de suas subjetividades no âmbito do psiquismo e da relação do sujeito com os objetos internos do funcionamento psíquico. Por último, as considerações finais como um conjunto de reflexões trazidas sobre a compreensão acerca do tema das massas, dos sujeitos e dos líderes no caso estudado.

É importante ressaltar, por fim, que a separação do texto nas duas dimensões selecionadas é uma opção organizacional e analítica, não pretendendo diminuir a relevância das dimensões traumática e interpessoal — presentes segundo a obra selecionada de Coelho Junior e Figueiredo -, ou pensar que a experiência subjetiva possa ocorrer separada em etapas, uma vez que todas as quatro estão em constante intersecção e se relacionam de forma suplementar durante as experiências.

A dimensão tratada neste tópico deve ser pensada como as coisas primeiras, que aparecem antes do próprio sujeito no mundo, antecedem-no e ultrapassam-no, sendo o Outro um constituinte da experiência subjetiva e intersubjetiva e que aparecerão no incidente da Pedra Bonita, uma vez que este se situa num tempo e espaço como uma experiência social e histórica. Assim, o plano da dimensão transubjetiva pode ser pensado da seguinte forma:

Nesse plano não há uma escolha, somos lançados, estamos jogados nessa forma de compreensão implícita que acaba por nos constituir no contexto de uma tradição, e onde vivemos sob a tutela do impessoal, das Man. É um campo de possibilidades que cria e delimita as condiçóes de nossa experiência e o horizonte de nossos atos. 
Uma certa alteridade é presença constitutiva das subjetividades na medida em que a tradição que nos precede e nos envolve deva ser compreendida como aquilo que não sendo eu faz com que eu possa vir a ser o que sou [...] (COELHO JÚNIOR; FIGUEIREDO, 2004, p. 18).

Tais autores também apontam que parece haver um consenso entre diversos estudiosos dessa dimensão de que há uma alteridade inaugural, portanto, anterior à existência do $\mathrm{Eu}^{2}$, que deve ser considerada ao pensar as relações intersubjetivas.

Tratando-se de um movimento sebastianista e milenarista, é essencial, antes de tudo, percorrer a tradição herdada historicamente que possibilitou as condiçôes para a experiência de Pedra Bonita. A partir de referenciais e representações simbólicas, legadas pela tradição cristã e portuguesa, os papéis, as expectativas, as imaginações e normatização das relações interpessoais poderão inserir-se num âmbito do socialmente possível. Nesse sentido, antes mesmo de avançarmos para as questóes intrapsíquicas estabelecidas nesta experiência, nos ocuparemos momentaneamente de contextualizar o panorama histórico da época para que situemos os elementos que possibilitaram a ocorrência desse evento.

Primeiramente, pensar a força que a cultura cristã tem nas sociedades oriundas de colonização portuguesa nos ajuda a identificar algumas representaçôes simbólicas que foram utilizadas no evento de Pedra Bonita, a saber: a ideia de salvação que se relaciona com a ima gem de Dom Sebastião; a ideia do sacrifício como fonte de religiosidade, ainda mais quando relacionada com a imagem de Cristo; e a imagem do messias. Toda essa construção mítica faz parte do imaginário dos sujeitos e é tributária da tradição cristã que influenciou grupos messiânicos e milenaristas.

Mas há de se destacar, sobretudo, duas coisas em comum entre os grupos messiânicos: a primeira, ainda que soe óbvio, diz respeito à ideia da volta do messias, i.e., símbolo encantado e libertador, o qual serviria como depositário de fé e esperança e "com capacidade para mudar a ordem das coisas e trazer paz, justiça e felicidade” (DE JESUS; FREIRE; SANTOS, 2009 , p. 2); e a existência de um líder cujas atribuições se diferenciavam das dos demais membros do grupo, muitas vezes sendo atribuiçôes de ordem mágica, ritualística ou sobrenatural (incluindo, em diversos casos, a capacidade de mediar contatos e/ou desencantar ou resgatar o

2 "Cada uma dessas diferentes concepçôes de Scheler, Heidegger e Merleau-Ponty apontam para uma matriz intersubjetiva que concebe a alteridade como inaugural e anterior, como um solo trans-subjetivo, anterior inclusive à possibilidade instituída de um eu que venha a se opor ou a se relacionar com um outro" (COELHO JUNIOR; FIGUEIREDO, 2004, p. 20). 
O messianismo sebastiânico no Reino da Pedra Bonita (1836-1838): discussões e interpretações a partir de uma bibliografia psicanalítica

perdido messias). A figura do líder ser-nos-á central, pois Freud argumenta que a natureza da massa é incompreensível se o negligenciamos (FREUD, 2011, p. 62).

Esses dois elementos-chave nos grupos messiânicos não se furtam ao caso do Reino da Pedra Bonita, em que os líderes João Antonio dos Santos, seu cunhado, João Ferreira, e Pedro Antônio, até o dia da dissolução da seita, gozavam não apenas da liderança grupal, mas das pressupostas habilidades de (re)invocar Dom Sebastião, o messias dos países lusófonos.

Nesse caso, há uma especificidade, dentro da tradição cristã, que se encontra nesses povos: o sebastianismo. Este fenômeno advém da história de Dom Sebastião, Rei de Portugal, que, ao desaparecer em campo de batalha - em Alcácer-Quibir, no Marrocos -, acabou se tornando um símbolo semelhante ao do messias, aquele que retornaria para trazer a salvação ao seu povo. O messianismo e o milenarismo no Nordeste brasileiro tomaram forma a partir de "[...] movimentos típicos de sociedades tradicionais, de base patrimonialista e estruturalmente assentados em parentelas, motivados pelas crenças do catolicismo popular" (NEGRÃO, 2001, p. 120). Alguns elementos do sebastianismo tão logo estão alinhados ao milenarismo, ou seja, à antiga visão, no escopo da escatologia cristã, que sugere que o messias Jesus Cristo há de voltar instaurando um reino cuja duração fosse de mil anos na Terra. O término desse período seria marcado pelo Juízo Final.

Portanto, a fusão da cultura cristã e da imagem de Dom Sebastião dão as bases de uma experiência comum herdada através da tradição e da alteridade que esses sujeitos terão como repertório para que a imaginação individual também se configure como um imaginário social, de símbolos comuns que também possibilitarão o diálogo e as ações em conjunto no Reino da Pedra Bonita.

\section{DIMENSÃO INTRAPSÍQUICA}

O foco deste tópico está na investigação intrapsíquica dos sujeitos, ou seja, onde investigaremos brevemente as instâncias do psiquismo (Id, Ego e Superego) e os objetos internos da própria psique do sujeito e que possuem efeitos nas atitudes e comportamentos ${ }^{3}$. Tal

3 "Esta dimensão intersubjetiva refere-se, fundamentalmente, ao plano das instâncias do psiquismo (Id, Ego e Superego), ao dos objetos internos e, de modo geral, ao que em psicanálise denomina-se como o modo object-relating de funcionamento psíquico. Ou seja, na teorização psicanalítica é possível conceber uma dimensão da experiência intersubjetiva em que a presença de objetos (no caso, outros sujeitos, ou ao menos partes deles) 
investigação partirá da unidade da massa para, então, olhar mais detidamente para os líderes (os reis) e os súditos, apontando para alguns elementos que reportam a esta dimensão da sub jetividade humana não de forma isolada, mas considerando alguns aspectos históricos e simbólicos que caracterizaram o episódio.

\subsection{A massa (ou a unidade)}

A leitura dos historiadores, via de regra, consiste em designar o episódio a que nos referimos como um movimento sebastianista, o que, é claro, está correto. No entanto, é de suma importância partir da memória e da historiografia sobre o Reino da Pedra Bonita para refletir as estruturas, relações e mecanismos presentes no grupo ou na massa e nos papéis desempenhados pelos principais agentes - os lideres —, todos os quais podendo ser bem elucidados segundo uma dimensão intrapsíquica, i.e., seguindo uma abordagem tradicionalmente psicanalítica.

Para tanto, as reflexões de Eugène Enriquez (1999) são um bom ponto de partida, uma vez que trataremos esse movimento sebastianista, daqui para frente, como massa, e que, muitas vezes, assume feiçóes e características da horda primitiva referida por Freud no Totem e Tabu (2012) e no texto Psicologia das Massas e Análise do Eu (2011), especialmente a partir do declínio desse movimento.

A ideia do reino tomou forma a partir de um suposto contato onírico de João Antônio dos Santos, o qual lhe revelou que Dom Sebastião estaria encantado nas duas pedras presentes no sítio do porvir Reino da Pedra Bonita. Conhecedor do mito sebastiânico, propagou seu testemunho nas cercanias de São José de Belmonte, no entanto, revelando que o desencanto do messias só seria possível conquanto fosse instalado um reino para sua volta, e os indivíduos - a serem contemplados com os presentes divinos do benevolente Sebastião contribuíssem com o derramamento de sangue nas pedras encantadas, como os sacrifícios e oferendas aos deuses que compõem o panteão ameríndio.

As promessas do messias, mediadas pelo então rei João Antônio e seus sucessores, legitimaram suficientemente os fatos ocorridos no reino; o imaginário comum da massa era abastecido diariamente pela esperança do retorno do tão-esperado e de vislumbre da concretização das promessas. Desse modo, “a massa 'está sujeita ao poder verdadeiramente mágico das

não precisa se dar efetivamente na realidade externa para que tenha efeito e produza consequências em termos psíquicos." Ibid. 
O messianismo sebastiânico no Reino da Pedra Bonita (1836-1838): discussões e interpretações a partir de uma bibliografia psicanalítica

palavras, que podem evocar as mais formidáveis tempestades na mente grupal, sendo também capazes de apaziguá-las”” (FREUD apud ENRIQUEZ, 1999, p. 56). Freud aponta que há uma predisposição (no nível intrapsíquico) ao mau, que potencializa-se quando emerge precisamente através das massas e que, no caso estudado, seriam identificadas como as negaçóes individuais dos próprios egos, substituídas pelas projeções de egos ideais presentes nas figuras e discursos dos líderes da massa.

\footnotetext{
Somos levados a pensar que a massa, em qualquer circunstância, se deixa guiar quase que unicamente pelo inconsciente, enquanto o indivíduo se guia unicamente pela razão, ou pelo menos 'reprime suficientemente suas tendências inconscientes', sob a condição de não as incorporar à massa (ENRIQUEZ, 1999, p. 57).
}

Enriquez enfatiza o poder que o discurso possui, isto é, compreendendo que a linguagem empregada pelos líderes (e o caráter mágico de suas palavras) remete à neurose narcísica dos indivíduos da massa e instalam algo que é central no caso do Reino da Pedra Bonita: o desaparecimento da noção de impossivel e das investigações racionais sobre os discursos e práticas normatizadas.

Freud sugere que a massa recrudesce algumas características presentes na horda primeva:

[...] Falta de autonomia e de iniciativa de cada indivíduo, a similitude entre a sua reação e a de todos os demais, seu rebaixamento a indivíduo de massa [...], o enfraquecimento da aptidão intelectual, a desinibição da afetividade, a incapacidade de moderação e adiamento, a tendência a ultrapassar todas as barreiras na expressão de sentimentos e a descarregá-los na ação (FREUD, 2011, p. 60).

A volta de um prometido messias que subjaz duas pedras supostamente encantadas parece plausível à massa e, mais do que isso, se o Sebastião não se revelou em carne e osso ainda, seria em decorrência das falhas e insuficiências individuais e da massa com o não cumprimento dos requisitos estabelecidos pelo quase totêmico rei. Os súditos do reino encantado não se apercebiam de algo estranho à ordem natural das coisas - isto é, o movimento biológico e natural dos entes - , ou não se punham a questionar a veracidade do discurso dos reis: com isso, "o pensamento estabiliza-se, portanto, num nível dogmático e trivial. [...] Os grupos evitam a dolorosa conjugação do primitivo e do sofisticado [...]” (BION, 1969, p. 179), de modo que ser-lhes-ia natural a sedução pelo discurso expressivo daquele sujeito (mais do que um mero partícipe da massa) cuja garantia fosse a existência e a volta de Dom Sebastião. Ten- 
taremos, adiante, compreender melhor o papel das lideranças do Reino da Pedra Bonita, bem como trazer alguns significados do termo messias, buscando concatenar alguns elementos teóricos com os fatos históricos.

\subsection{Os líderes da massa: os reis e o(s) messias}

A definição do termo messias, segundo o dicionário Aurélio (2011), é: "subst. masc. Pessoa a quem Deus comunica algo de seu poder ou autoridade”; segundo o Michaelis On-line (2018): “[...] (3) Pessoa esperada ansiosamente. (4) Indivíduo que se apresenta como líder ou reformador social, colocando-se à frente de um movimento religioso, político, social etc"; ou, ainda, pode ser entendido à luz da tradição judaica como “[...] o rei do reino de Deus na Terra, reino de paz e justiça. Os judeus esperam o Messias no fim dos tempos [...]. Do hebraico 'Messias' = o Ungido" (SCHWIKART, 2001, p. 71). O que torna-se claro ante as definições é que, em qualquer recorte temporal, o messias representa liderança terrena sob os desígnios divinos, ou seja, é aquele indivíduo situado num nível ontológico único, flutuante, cujas atribuições medeiam o deus (sagrado) e os humanos (profano).

No Reino da Pedra Bonita, todavia, há uma sutil inversão de papéis e ambivalência do sentido de messias: ora, o messias (Sebastião) é líder e é ungido, já tocado por um contato divino a partir do qual se fará valer o reino de Deus na Terra. Quem o reivindica, e isto fique claro, são os líderes da massa, ou seja, os reis João Antonio dos Santos, seu cunhado, João Ferreira, e Pedro Antônio. João Antônio, o primeiro líder, recebe esse material através de um contato onírico, que é sempre suscitado em seus discursos e transmitido de forma persuasiva à massa, e que permeia o imaginário dos seguidores mesmo após sua renúncia e a assunção dos dois líderes seguintes: emergiu nele uma consciência psíquica persecutória e esquizoparanóide.

Reportando a Adriana Salvitti, "Bion nota que na posição esquizoparanóide haveria a expressão de um simbolismo rudimentar ou de um pré-simbolismo semelhante ao material onírico, capaz de proporcionar alguma consciência da realidade psíquica [...]” (SALVITTI, 2011, p. 60-61). Os dois líderes seguintes cravam essa inversão de papéis, ou, digamos, alteração nos níveis ontológicos: tornam-se o messias do (agora) Deus-Sebastião. Mas há algo fundante no cerne da imagem de messias, nunca a ser desconsiderado: para que cumpra sua função, é preciso manter-se por nascer, ou seja, ao se revelar, tende a ir à cruz, ser morto, ser deposto ou ostracizado. No Reino, João Antonio dos Santos fugiu a evitar sua morte; seu cu- 
O messianismo sebastiânico no Reino da Pedra Bonita (1836-1838): discussões e interpretações a partir de uma bibliografia psicanalítica

nhado, João Ferreira, foi assassinado por Pedro Antônio que, por sua vez, assumiu o Reino e, pouco depois, também foi assassinado (ainda que por razóes diferentes).

Bion é fundamental à elucidação dos líderes e seus papéis no grupo - bem como o funcionamento ensimesmado de grupos - , principalmente tangenciando-os ao nível da valência (inconsciente) e dos pressupostos básicos. Ainda que houvesse coexistência e ciclicidade dos três pressupostos (dependência, acasalamento e luta e fuga), é nítida a prevalência do suposto básico de acasalamento.

O suposto do acasalamento, nos termos bionianos, pode ser interpretado de duas formas no Reino: tanto a partir da relação rei-rainha, em que estes produziriam uma noção de aristocracia ${ }^{4}$, cujas ideias reforçavam a esperança messiânica no grupo; quanto na relação reimessias, em que pesasse a força quase divina produzida na fusão dos dois entes (evidentemente, instaura-se a ausência de impossibilidades). Este acasalamento é condição sine qua non à inversão dos níveis ontológicos, descrita anteriormente: o rei acasalado ao messias reivindica atributos deste, promovendo a si mesmo messias do já Deus-Sebastião, todavia, rompendo com este presunçoso acasalamento apenas no momento de sua morte.

$\mathrm{O}$ assassinato dos líderes demonstra, com efeito, o rápido entremeamento dos supostos bionianos: aqui, a massa assume uma posição esquizoparanóide intimamente ligada aos instintos primordiais, explicadas à luz do suposto de luta e fuga em que se legitima a luta e a morte do líder tirano, ou falsário (porque se proclamou messias); a luta e fuga da massa, nesse momento do Reino, triunfou sobre o acasalamento cabal entre o rei e Sebastião.

\subsection{Os seguidores: súditos do Reino da Pedra Bonita}

Como é colocado pelos estudiosos dos eventos de Pedra Bonita, o reino possuía por volta de trezentas a quatrocentas pessoas que seguiam João Antônio como seu rei e viviam ali, submetendo-se às leis próprias do local e mantendo uma devoção política e religiosa à fé sebastianista. Inicialmente, os sebastianistas mantinham sua devoção através da contemplação e da oração naquele lugar sagrado, porém, com o tempo, o ritual de sacrifício de vidas humanas passou a ser também utilizado, acreditando que o sangue seria capaz de desencantar as pe-

$4 \quad$ Ibid. p. 178. Quanto ao emprego do termo aristocracia para o suposto do acasalamento, Bion justifica que "a função desse subgrupo é fornecer uma saída [ao grupo] para sentimentos que se concentram em torno das ideias de procriação e nascimento, isto é, para a esperança messiânica [...]” (p. 178). 
dras e trazer de volta Dom Sebastião, o messias, que estaria encantado nelas. Dentre os sacrificados estavam homens, mulheres e crianças. Numa das descriçóes destes rituais feita por um estudioso do assunto, destaca-se a prática de pegar crianças e colocá-las asas, feitas de palha, e atirá-las de cima das pedras, dizendo que seriam anjos (RTV Caatinga Univasf, 2018).

Os relatos impressionam pela quantidade de seguidores que João Antônio conseguiu rodear-se através da crença recebida por ele e, também, pela gravidade dos atos cometidos em nome dessa fé sebastianista nos rituais, que chegaram a sacrificar por volta de cinquenta pessoas voluntárias e involuntárias. Assim, nos são impostas duas questões: como foi possível esse volume de pessoas aceitar submeter-se a estes líderes e suas regras e, também, o que as levou a realizar os atos de sacrifício em nome da crença sebastianista?

Para sugerir algumas pistas às questóes levantadas, a partir de uma análise na dimensão intrapsíquica, é interessante recorrer aos estudos de Melanie Klein, primeiramente tratando-se de como teria sido possível que tantos sujeitos distintos submeteram-se às lideranças de Pedra Bonita.

Nos excertos de Money-Kyrle, em Psicanálise e ética, através da psicanálise de Freud e Klein, o autor reflete se um tipo de consciência pode ter relação com um modo de se portar socialmente ou com um tipo de moral política. O que nos interessa nesses estudos é a ideia de construção do superego, pois ela está relacionada com a introjeção de uma autoridade e a culpa que sentimos diante dela:

A esse pai “introjetado" deu Freud o nome de superego. Em sua opinião, é o guar dião necessário da moralidade; mas quando excessivamente desenvolvido, condena a pessoa à doença mental e, assim, derrota uma parte de seu próprio intento, que é transmitir as solicitaçôes tanto positivas como negativas da sociedade em que vivemos (MONEY-KYRLE, 1969, p. 151).

Não é possível a nós reconstituir a construção do superego dos seguidores - e nem é esta a intenção - , contudo, o que nos interessa é o raciocínio que se deriva dessa apreensão do superego. Percebemos que os indivíduos que desenvolvem uma consciência, na qual a culpa está fortemente atrelada ao medo da figura autoritária, tendem a obedecer inquestionavelmente aos mandos autoritários de modo a nutrir a ilusão de serem amados igualmente pelo líder (FREUD, 2011, p. 67), pois

O líder da massa continua a ser o temido pai primordial, a massa quer ainda ser dominada com força irrestrita, tem ânsia extrema de autoridade, ou, nas palavras de 
O messianismo sebastiânico no Reino da Pedra Bonita (1836-1838): discussões e interpretações a partir de uma bibliografia psicanalítica

Le Bom, sede de submissão. O pai primevo é o ideal da massa, que domina o Eu no lugar do ideal do Eu (FREUD, 2011, p. 71).

O que se encontra nesta situação é o que podemos chamar de uma consciência autoritária, pois o elemento persecutório na culpa é predominante; é provável, portanto, que boa parte dos seguidores sebastianistas no caso de Pedra Bonita, em busca de obedecer a suas crenças e morais internas, temesse desobedecer aquele que se dizia ser o representante da voz de Dom Sebastião. Desse modo, suas subjetividades se submetiam às regras e aos rituais que a autoridade quase totêmica dos líderes lhes designasse da forma mais disciplinada.

Somente esta análise também não explica a segunda questão de como foi possível realizar os atos de sacrifício em nome do retorno de Sebastiâo. Sem dúvida, uma consciência autoritária coletiva, que está mais propensa a obedecer seus líderes, tenderá a realizar os atos exigidos por estes líderes evitando questioná-los. Porém, é preciso pensar outros objetos internos da psique dos sujeitos que os levam a abrir mão da própria vida, no caso dos sacrifícios voluntários, ou de tirar a vida de outros em nome de suas crenças.

Nos estudos sobre o sistema kleiniano (1969), é apontado que os sujeitos lidam "com seus objetos internos e externos mediante estratégias e mecanismos peculiares a cada uma das posições”, sendo as fantasias inconscientes aquilo que funcionará como arranjos psíquicos do inconsciente para lidar com as pulsões do psiquismo causadas pelas vivências e também a expressão direta dessas pulsões. Dito isso, as fantasias assumem um papel importante nos impulsos e na vida cotidiana dos sujeitos. Ao mesmo tempo, outro pensamento que nos interessa aqui é a ideia de uma posição esquizoparanóide. Esta posição pode ser definida como uma dinâmica que através dos

[...] mecanismos de cisão e projeção, envolve o movimento predominante de livrarse do acréscimo de estímulos por caminhos mais rápidos e violentos, que levam à descarga e ao esvaziamento de excitações, necessários à homeostase e à estabilização entrópica do aparelho psíquico (CINTRA; FIGUEIREDO, 2010, p. 148).

Quando relacionamos essa necessidade de livrar-se de estímulos que causam desequilíbrio no aparelho psíquico com as projeçôes feitas através das fantasias inconscientes, podemos pensar numa forma de interpretar como o Reino de Pedra Bonita operou esses sacrifícios.

Além da consciência autoritária coletiva, havia naquele reino uma projeção relativa ao líder e, também, à vinda do messias Dom Sebastião, cuja presença significaria a realiza- 
ção de diversos desejos, bem como a própria realização da idealização do paraíso. Porém, o messias não se apresentara (como seu nível ontológico prevê); essa imagem da busca da realização de desejos e pulsões, cujas possibilidades de suas realizações se ausentam, é similar à imagem que Klein pensa sobre o bebê que deseja o seio da mãe, mas não pode tê-lo por estar ausente.

Assim, as fantasias servem como estratégias de projetação de formas; estratégias de possibilitar a presença de Dom Sebastião ali para a realização daquele paraíso desejado. O desequilíbrio precisava retornar ao equilíbrio, assim os sacrifícios podem servir como essa descarga fantástica, exigida pela posição esquizoparanóide, em busca do equilíbrio que seria provocado pela presença do messias assim que o sangue dos sacrificados desencantasse as pedras.

Dom Sebastião não retornou, sobre isso não há dúvida. Tais signos míticos - do retorno de um passado glorioso, de uma Idade do Ouro, de um reino de mil anos, enfim - per maneceram acesos apenas nas estruturas imaginárias. Ao mesmo tempo, os sacrifícios se tornaram tão frequentes que acabaram, inclusive, por desejar o sangue dos próprios líderes em busca de tal realização.

\section{$4 \quad$ CONSIDERAÇÕES FINAIS}

A análise de relações humanas sempre perpassa inúmeras formas de interpretálas. Frederic Munné (2008) propóe um modelo prismático para se pensar o objeto da Psicologia Social, superando a já obsoleta obsessão de enxergá-lo na intersecção entre Psicologia e Sociologia, e propondo a compreensão deste objeto somente a partir da assunção das múltiplas facetas que se desvelam como possibilidades de explicá-lo; analogamente, ao pensar as relações humanas, podemos olhar para o âmbito histórico, espacial, cultural, psíquico etc. e, dessa for ma, é possível se olhar para um fenômeno a partir de ângulos (como um prisma) e objetivos diferentes. No caso deste trabalho, preocupamo-nos em olhar o incidente do Reino da Pedra Bonita sob a ótica das relações intersubjetiva e intrapsíquica - segundo método presente nas obras trazidas de Coelho Junior e Figueiredo, Eugène Enriquez e Sigmund Freud -, que nos possibilitou transitar por diferentes dimensões das relações humanas.

A partir da dimensão transubjetiva, verificamos que o contexto histórico das relações de miséria no sertão, somado às esperanças em imaginários históricos herdados pela cultura - nesse caso a cristã -, em que surgem mitos como o sebastianismo (de um messias redentor e capaz de construir um reino milenarista, ou seja, uma utopia divina encabeçada por 
O messianismo sebastiânico no Reino da Pedra Bonita (1836-1838): discussões e interpretações a partir de uma bibliografia psicanalítica

um líder), possibilitou que, através dos símbolos e significados, os discursos e as práticas que se formassem ali revelassem um apelo para o surgimento de uma massa muito específica, dotada de uma psicologia também singular.

Essas relaçóes intrapsíquicas, que foram estudadas e tecidas ao longo do artigo, demonstraram ser propícias em ambientes de massas que estimulam um comportamento na crença de um líder com a figura do messias. Tanto os seguidores quanto aqueles que lideraram o movimento acabaram por ser afetados pelas relaçóes que se criaram, sendo os efeitos os de abdicação do ego e esvaziamento de suas identidades e subjetividades para fazer parte de um coletivo cuja consciência fosse autoritária e esquizoparanóide, levando a açôes irrefletidas que foram numa direção contrária a que se acreditaria ser o mais humanitário. 


\section{REFERÊNCIAS BIBLIOGRÁFICAS}

BION, W. Capítulo 7: Dinâmica do grupo: uma Revisão. In: KLEIN, M. et al. Temas de psicanálise aplicada. Rio de Janeiro: Editores Zahar, 1969.

COELHO JUNIOR, N. E.; FIGUEIREDO, L. C. Figuras da intersubjetividade na constituição subjetiva: dimensões da alteridade. Interaçôes, São Paulo, v. 9, n. 17, p. 9-28, jun. 2004.

DE JESUS, J.; FREIRE, M. A. L.; SANTOS, R. O Reino Encantado da Pedra Bonita. Aracaju: Universidade Tiradentes, 2009.

ENRIQUEZ, E. Da horda ao Estado: Psicanálise do vínculo social. Rio de Janeiro: Jorge Zahar, 1999.

FERREIRA, A. B. H. Aurélio: dicionário escolar da Língua Portuguesa - 2a ed. Curitiba: Positivo, 2011.

FREUD, S. Psicologia das massas e análise do Eu e outros textos. São Paulo: Companhia das Letras, 2011.

FREUD, S. Totem e tabu. São Paulo: Companhia das Letras, 2012.

MICHAELIS. Dicionário Brasileiro da Lingua Portuguesa. Disponível em: http://michaelis.uol.com.br/moderno-portugues/busca/portugues-brasileiro/messias/. Acesso em: jun. 2018.

MONEY-KYRLE, R. Capítulo 6: Psicanálise e ética. In: KLEIN, M. et al. Temas de psicanálise aplicada. Rio de Janeiro: Editores Zahar, 1969.

MUNNÉ, F. La Psicologia Social como ciência teórica. Barcelona: PPU, 1994.

NEGRÃO, L. N. Revisitando o messianismo no Brasil e profetizando seu futuro. Revista Brasileira de Ciências Sociais, v. 16, n., 46, p. 119-129, 2001. 
O messianismo sebastiânico no Reino da Pedra Bonita (1836-1838): discussões e interpretações a partir de uma bibliografia psicanalítica

RTV Caatinga Univasf. Memória Sertão Pedra do Reino, em São José do Belmonte. Youtube. 27 fev. 2018. Disponível em: https://www.youtube.com/watch?v=J0C9ecYfqRE\&t=301s. Acesso em: jun. 2018.

SALVITTI, A. Psicose e ética do pensador na clínica de Bion: panorama dos artigos dos anos 50. Revista Impulso, Piracicaba, v. 21, n. 52 p. 57-64, 2011.

SCHWIKART, G. Dicionário ilustrado das religiōes. Trad. C. Bovo. Aparecida: Editora Santuário, 2001.

ULHOA CINTRA, E. M.; FIGUEIREDO, L. C. Capítulo Considerações gerais sobre alguns aspectos do conjunto do sistema Kleiniano. In: Melanie Klein: Estilo e Pensamento. São Paulo: Escuta, 2010. 